\title{
Ethnography and Organizational Ethnography: Research Methodology
}

\author{
Anuruddika Jayathilaka \\ The University of Sri Jayewardenepura, Gangodawila, Nugegoda \\ Email: anuruddikadec26@gmail.com
}

How to cite this paper: Jayathilaka, A. (2021). Ethnography and Organizational Ethnography: Research Methodology. Open Journal of Business and Management, 9, 91-102.

https://doi.org/10.4236/ojbm.2021.91005

Received: September 26, 2020

Accepted: December 20, 2020

Published: December 23, 2020

Copyright $\odot 2021$ by author(s) and Scientific Research Publishing Inc. This work is licensed under the Creative Commons Attribution International License (CC BY 4.0).

http://creativecommons.org/licenses/by/4.0/

\begin{abstract}
Ethnography is a branch of anthropology which is a systematic study of distinct philosophies. Ethnography explores cultural phenomena from the point of view of the subject of the study. Unlike the other research methodologies adhered, ethnography or organizational ethnography dives into the culture of the subject of the research study and excavate the truth from the facts seen, heard or felt. Through this paper, the researcher wanted to highlight the value created by using ethnography in a study using the existing literature. Also, another objective was to explore ethnographer's self and role in the eyes of other researchers who had been using ethnography in their studies.
\end{abstract}

\section{Keywords}

Ethnography, Organizational Ethnography, Ethnographer

\section{Introduction}

\subsection{Background of the Study}

In recent years, academic and professional researchers have looked to ethnography to provide a perspective on relations between human and other phenomena in context. For some ethnography is simply a fashionable term for any form of qualitative research while for others it is less about a method and more about the lens through which the human activities are viewed (Blomberg, Burrel, \& Guest, 2009). Within this paper value created by using ethnography is highlight by including ethnographer's self and role as well. This will finally let the reader to get a basic but comprehensive knowledge before incorporating ethnography or organizational ethnography in a research study.

\subsection{The Research Problem/Research Question}

"What is the role of Ethnography and Organizational Ethnography as Research 
Methodology?" is the research question that the author is focusing on throughout the research study. The research study aims: firstly, to highlight the value created by using ethnography in a study using the existing literature, to explore ethnographer's self and role in the eyes of other researchers who had been using ethnography in their studies.

\section{Methodology}

In order to achieve the above-mentioned research objectives of the study, a comprehensive literature survey was conducted incorporating desk research strategy in addition to the rational thinking of the author and observations. A countless of literature related to theory and practices of Ethnography and Organizational Ethnography is available in various publications and conferences. The author searched for the articles related to Ethnography and Organizational Ethnography using the search criteria, the author has used the three main terms related to Ethnography and Organizational Ethnography: "Ethnography", "Organizational Ethnography", "Ethnographer".

\subsection{Ethnography}

Ethnography is not a quick dip into a research site using surveys and interviews, but an extended period time in which the ethnographer immerses herself/himself in the community she/he is studying: interacting with community members, observing, building relationships, and participating in community life (Cunliffe, 2010). Accordingly, the researcher then has to translate that experience so that it is meaningful to the reader and this is not achieved by testing propositions and generating predictive and generalizable knowledge and not by "fording a stream that separates one text from another and changing languages in midstream" (Cunliffe, 2010) but telling a convincing story using the language of community members and by weaving observations and insights about culture and practices into the text (Cunliffe, 2010). It is also described that ethnography involves an ongoing attempt to place specific encounters, events, and understandings into a fuller, more meaningful context (Seneviratne, 2010). It is not simply the production of new information or research data, but rather the way in which such information or data are transformed into a written or visual form (Seneviratne, 2010). As a result, it combines research design, fieldwork, and various methods of inquiry to produce historically, politically, and personally situated accounts, descriptions, and representations of human lives (Seneviratne, 2010). As an inscription practice, ethnography is a continuation of fieldwork rather than a record of past experiences in the field (Seneviratne, 2010). Because ethnography is both a process and a product, ethnographers' lives are embedded within their field experiences in such a way that all of their interactions involve moral choices (Seneviratne, 2010).

It is said that traditional ethnographic approaches have been critiqued for reproducing colonial agendas in relation to exploiting and othering socially mar- 
ginalized groups, and subsequently producing knowledge which was unrepresentative of local ways of knowing and being, and unreflective of community goals (Huff, Rudman, Magalhães, Lawson, \& Kanyamala, 2020). In the 1930s, the critical sociologists of the Chicago school introduced a new stream of ethnographic studies when they started to explore their own street corners just as if they were unknown places (Eriksson \& Kovalainen, n.d.). Currently, the field sites of ethnographic research can be anywhere, including familiar settings. Ethnographic research can take place in many types of communities including formal and informal organizations such as workplaces, urban communities, fan clubs, trade fares, shopping centers, and social media. In addition, the research is often performed in the native language of the researcher (Eriksson \& Kovalainen, n.d.).

Ethnography more broadly is concerned with the study of social interactions and culture from the perspective of naturalism, within humanistic, hermeneutic and interpretivist paradigms (Kalou \& Sadler-Smith, 2015). The roots of ethnography lie in anthropological studies that focused on studying social and cultural aspects of small communities in foreign countries. The researchers lived among the inhabitants with the purpose of understanding the culture that these people shared. Thus, the classic anthropologists were foreigners in their field sites (Eriksson \& Kovalainen, n.d.). Ethnographic research takes a cultural lens to the study of people's lives within their communities (Eriksson \& Kovalainen, n.d.). Its empirical aims are to capture and make sense of the perspectives and practices of people "in vivo" (Kalou \& Sadler-Smith, 2015). The essence of ethnography is an endeavor to represent "the social reality of others" (Kalou \& Sadler-Smith, 2015) in terms of interactions, artefacts, actions, symbols, and language of organizational members (Kalou \& Sadler-Smith, 2015). This is based on a need to "achieve access to the native's point of view" (Sandiford, 2015). So, there will inevitably be a certain tension between trying to find the native's way of understanding the world and interpreting this from a scholarly, theoretical perspective (Sandiford, 2015).

Ethnography exists in many forms and ethnographers continuously debate about what counts as ethnography, and "how to represent the field" (Eriksson \& Kovalainen, n.d.). As a result, there are distinct versions of ethnographic research that have their own epistemological backgrounds and varied research practices (Eriksson \& Kovalainen, n.d.). Eriksson and Kovalainen (n.d.) identify types of ethnography such as: theoretically informed approaches which rely on the principles of critical theory, "critical ethnographies" and feminist theory, "feminist ethnographies"; "autoethnography" refers to an approach where the researcher's personal and reflective perspective is part of the analysis; the expansion of the Internet and social media has boosted researchers to perform virtual ethnography or netnography. Therefore, if you plan to do an ethnographic study, you will need to specify what kind of ethnographic research you wish to ${ }^{1}$ In the living body of a plant or animal; in a real-life situation (Merriam Webster Dictionary). 
perform (Eriksson \& Kovalainen, n.d.). Eriksson and Kovalainen (n.d.) identify a separate category which is business-related ethnographic research where he identifies workplace, industrial and organizational ethnographies (Yanow, Ybema, \& Van Hulst, 2012) which provide in-depth descriptions on a wide range of topics within the field of management and organizations, such as managerial action, organizational cultures, interaction of professional groups, work behavior and coworker relations, emotional labour, and sexual harassment. Organizational ethnography is done within a structured work situation are different from those that affect other areas of social life (Bryman \& Bell, 2007).

\subsection{Organizational Ethnography}

Bryman \& Bell, 2007 understands organizational ethnography to be distinctive because it is concerned with social relations that are related to certain goal-directed activities. He suggests that the rules, strategies and meanings within a structured work situation are different from those that affect other areas of social life. It is also defined organizational ethnography as the art of exploring the complexities of everyday organizational life through immersion (Ybema \& Kamsteeg, 2009). Some are also emphatic that organizational ethnography requires a well-balanced concern with the play between context, self and other as they thread themselves across the warp and weft of communication (Linstead, 2017). Organizational ethnography is also viewed as a methodology which joins political ethnography, educational ethnography and other such whose marking designates the kind of setting in which the ethnography is to be carried out, as well as, at times, the disciplinary domain that gives it a home by Yanow (2012). Cunliffe (2010) argues that good organizational ethnographies can reveal and explore the intricacies, challenges, tensions, and choices of life in organizations. They can offer interesting resonant tales that draw you into the lives of organizational members-like a good mystery but with insights about the way we manage, think about and conceptualize organizations (Cunliffe, 2010). However, the arguments supporting the potential of organizational ethnographic case studies to improve the process and increase the impact of qualitative research are currently underdeveloped (Elizabeth, Gaboury, Breton, \& Denis, 2020).

Even though organizational ethnography is not familiar it is not a new methodology to the research world. Writing detailed accounts of organizational life is a long-standing tradition, as others have also remarked (e.g., Ybema \& Kamsteeg, 2009). Notable among these accounts are the Hawthorne studies of the 1920s and 1930s and Elton Mayo's adoption of anthropological field methods, as well as ground-breaking, in-depth analyses published from the late 1940s to the early 1960s of the "informal organization" and the bureaucratic "underlife" (as cited in Ybema \& Kamsteeg, 2009). In The Dynamics of Bureaucracy; in TVA and the Grass Roots and Leadership in Administration are few of the writings which drew on those same methods described and discussed today in organizational ethnography papers and the growing numbers of text and other books 
treating it both methodologically and substantively (as cited in Yanow, 2009). A similar erasure of the methodological past among Industrial and Labor Relations programs, another member of the organizational studies' institutional family (Yanow, 2009).

Organizational ethnographers strive for an appreciation of the complexities of the everyday in organizational settings (Ybema \& Kamsteeg, 2009). Ybema and Kamsteeg (2009) have suggested that organizational ethnographers cherish their place on the margins of organizations and stay somewhat marginal, entering the field with an almost naive wonder about the way people think and act in organizations, and maintaining their engaged, yet simultaneously distanced, playful, and ironic stance because it provides a reflexive distance. They further argue that; for generating data, developing interpretations, and representing findings, ironies and mysteries that come up in the interplay between data and theory and between the researcher and the researched can be rich sources of inspiration which are clearly incorporated in organizational ethnography (Ybema and Kamsteeg, 2009). Seeing the extraordinary-in-the-ordinary may help to elicit curiosity about people "strangeness", as well as challenge the taken-for-granted logic of things, both the participants' and the researchers' (Ybema and Kamsteeg, 2009). Rather than trying to grasp the entire configuration of the organizational "village", organizational ethnographers seem increasingly oriented toward following the person (example: the CEO or other employee) or a specific organizational practice (example: the corporate culture coordinator) or an object or "fact" (Ybema \& Kamsteeg, 2009).

As Ybema \& Kamsteeg (2009) describe in the "Organizational Ethnography Studying the Complexities of Everyday Life" about the key characteristics of organizational ethnography. Combined fieldwork methods are the first which it is its conduct (undertaken to grasp complex organizational processes at their fullest through an equally complex set of methods) that gives organizational ethnography its specific flavor (Ybema \& Kamsteeg, 2009). Also, organizational ethnography is concerned to be "at the scene", Organizational ethnographers do not describe the complexities of everyday organizational life in the abstract, but instead through reporting on their first-hand, field-based observations and experiences (Ybema \& Kamsteeg, 2009). Another characteristic is hidden and harsh dimensions. In drawing close to subjects and situations, organizational ethnography has the potential to make explicit the often-overlooked, tacitly known and/or concealed dimensions of meaning-making, including its emotional and political aspects (Ybema \& Kamsteeg, 2009). Context-sensitive and actor-centered analysis is another salient feature of organizational ethnography which is about combining an orientation toward subjective experience and individual agency in everyday life with sensitivity to the broader social settings and the historical and institutional dynamics in which these emerge or are embedded (Ybema \& Kamsteeg, 2009). In practice ethnographers work to make sense of organizational actors' sense making, usually through the latter's own language 
and concepts, although these may be cast in the language of "culture", "identity", "scripts and schemas", "values, feelings, and beliefs", "interpretive models of and prescriptive models for reality", and the like which is the key character of "meaning-making" (Ybema \& Kamsteeg, 2009). Finally, and importantly, reflexivity and positionality, what an interpretive organizational ethnography offers is the understanding that we, as researchers, "call it [the world that we study] a grain of sand" (Ybema \& Kamsteeg, 2009).

Yanow (2009) has identified four challenges which are faced when doing organizational ethnography. First, the organizational ethnographer needs to be able to articulate the ways in which organizational ethnography is a sensibility and to work to delineate resisting the equation of ethnography with interviewing, more clearly. Then it is about defining "what is an organization?" In ways that make clear that organizational ethnography is not only about corporations (Yanow, 2009). This means not only including public sector services, local authorities, but also engages virtual and new media-mediated organizations; and the prospect of studying second life-based organizations and others. The third question is on how do traditional methodological concerns need to expand in order to encompass methods appropriate to contemporary organizational ethnographies? Traditional ethnographic inquiry rested on the unspoken assumption of face-to-face interaction while immersed in a single, bounded community (Yanow, 2009). New forms of organization challenge the methods inherent in these assumptions thus organizational ethnography needs to be able to give a methodological account of a range of surrogates for in-person relationships, from voice to writing to avatars that can be entirely fantastical, that are increasingly in use in today's organizations (Yanow, 2009). Finally, the challenge is identifying how organizational ethnography fits into current higher educational structures. According to the research study by Yanow (2009) in the USA, ethnographic research does not fit the Institutional Review Board (IRB) paradigm for doing science, which is based on an experimental research design model in which research participants come into the researcher's domain. This is a major challenge of using organizational ethnography in doing research.

\subsection{Role as an Ethnographic Researcher}

According to Seneviratne (2010) a researcher might decide to use the ethnographic method, if she or he has an epistemological position which suggests that knowledge or evidence of the social world can be generated by observing or participating in or experiencing "real life" settings, interactive situations and so on because not all knowledge is articulable, re-countable or constructible in an interview. She further argues that this position is based on the premise that these kinds of settings, situations and interactions reveal data in multidimensional ways. Because of shared experiences, participation or by developing empathy with the phenomena the researcher can be a "knower" in these circumstances. Mason (2002) identifies the same as "standpoint" position, "that is, that you are 
a 'knower' because you share relevant experiences, or because you have 'been there"'. They know what the experiences of the social setting feel like, and in that sense, they are epistemologically privileged (Mason, 2002). The ethnographic method emphasizes the fact that reality is socially constructed and indeed it facilitates the researcher to explore and understand multiple realties in the research setting.

The context of the study is employment of people with disabilities. According to Bryman and Bell (2007), an ethnographic approach implies intense researcher involvement in the day-to-day running of an organization, so that the researcher can understand it from the insider's point of view. Nevertheless, ethnographers believe that separating the facts from the fictions, the extraordinary from the common, and the general from the specific is best accomplished by lengthy, continuous, firsthand involvement in the organizational setting under study (Bryman \& Bell, 2007). When "ethnographying” within one's own culture and that is where organizational ethnography is often done-we are much more like fish trying to discover the water that surrounds us (Ybema, \& Kamsteeg, 2009). For organizational ethnographers, the very "un-strangeness" of the surroundings in their research prevents them from seeing it (Ybema \& Kamsteeg, 2009). So, when doing fieldwork in situations or settings that are or have become strongly familiar to us, strangeness is not a given but an achievement (Ybema \& Kamsteeg, 2009).

Ethnographic researchers immerse themselves in the setting and collect data directly and systematically by participating, watching, and listening attentively (Kalou and Sadler-Smith, 2015). Together with the social, emotional and bodily dynamics of ethnography, the intellectual issues involved in generating data through ethnographic fieldwork present a major challenge to the ethnographer (Seneviratne, 2010). In the face of such challenge, a framework developed by Mason (2002) where she identifies several clusters of questions, each woven around an important aspect of fieldwork, becomes an effective methodological tool to be used in designing and engaging in ethnographic fieldwork (as cited in Seneviratne, 2010). The clusters of questions are woven around, the nature of the phenomena, or entities, or social "reality" (finding the research setting), what might represent knowledge or evidence of the entities or social "reality" (generating knowledge and significance of the setting), topic or broad substantive area the research is concerned with (directing the ethnographic gaze), the intellectual puzzle and what is wished to do to explain or explore (getting in and getting by), the purpose of the research and the reason for doing it (identity, relationships, informed consent and turning observations into data/writing field notes) (Mason, 2002). Mason (2002: 22) further elaborates that "My 'difficult questions' are intended to express those key issues and to encourage that reflexive practice, but clearly they also establish an agenda of what I think is important in good research practice, and what I think it is possible for empirical research to do". She also assumes that research can be done well (or, by implication, badly), and that 
researchers can learn to do better research through experience, and through an active form of critical reflexive practice around key issues (Mason, 2002).

Being an organizational ethnographer in the field would be achieved by working in the context for a while. As per Bryman and Bell (2007) in order to become immersed in other people's realities, organizational ethnographers, engage in field work that tends to commit them to a period of time spent in the organization, or a long stay "in the field". Both socially and culturally, organizational ethnographers are often relatively close to the field being studied. They often solve the problems of accessing closed organizational circuits through drawing on connections in their personal networks, entering sites that are familiar to them, and/or becoming professional insiders or even full members of the organization (Ybema \& Kamsteeg, 2009). In doing so, they substitute the boundaries that kept them out with those that keep them in, thus facing the problem, as Mosse put it, "not of entering a different world so as to be able to imagine or infer the taken-for-granted... but of exiting a known world for the same purpose" (Ybema \& Kamsteeg, 2009). Being close to the "natives"-or even being natives themselves, as in the case of at home ethnography (Ybema \& Kamsteeg, 2009)_organizational ethnographers may have an easier access to culture members' own perspectives, while simultaneously experiencing more difficulties in divesting themselves of taken-for-granted understandings (Ybema \& Kamsteeg, 2009).

\subsection{Ethnographer's Self}

Before being an ethnographer in the field, it is needed to understand the role to be played as an ethnographer. Whilst the collection of memory and writing culture does not intend to be a systematic interrogation of the nature of the self, it does seek to reveal certain aspects of the self and, more specifically, the ethnographic self, through its focus on the role of experience and memory in ethnography (Collins \& Gallinat, 2010). The concept of self is relatively a modern development/ the self is a social construction.

Three questions, what kind of identity, status or role shall try to adopt, what impression should try to create and how should act, were introduced by Mason (2000) in order to question the concern on the "ethnographic self". With the participant-observer question, the researcher will not be able to decide them once and for all in advance (Mason, 2002). The questions also carry similar difficulties, in the sense that may be unable to control the ways in which the identity, status or role are perceived, and may find researcher himself constantly trying to negotiate and renegotiate them (Mason, 2002). For example, the researchers will need to decide whether they admit their status as a researcher while most ethical codes would suggest that the research should not be conducted in a covert or deceitful manner, but an overt role is not always easy or possible to maintain. Even in small groups, it is not always possible to preface every interaction or meeting with a few well-chosen words about the role as a researcher 
(Mason, 2002). Mason (2002) further explains that the researcher will need to think about the implications of his/her role(s) for data generation and for the ability to move around in the setting.

Further Mason (2002) explains that the researcher will also need to think about the practicalities of adopting such a role: is the researcher trained, can he/she perform the role adequately, will other characteristics-for example age, gender, ethnicity, religion, known views or allegiances-influence the ability to take on the role or to be accepted in it. Mason (2002) was mentioning about other less formal aspects of the identity, status or role which the researcher should think about. For example, what kind of demeanor is the researcher going to adopt in the setting, and in different situations? how is he/she going to behave? is he/she going to be enquiring, accommodating, aggressive, reticent, garrulous, and opinionated? what impression is the researcher going to try to create? According to Mason (2002) developing relationships in the research setting can be very difficult, and the way the researcher does this is likely to have significant implications for the kind of access actually achieve. The development of relationships in your setting will, at least in part, be governed by a range of social norms (Mason, 2002). Whatever the setting, it is inevitable that the researcher will get on better with some participants than others, and may actually be "adopted" by a "key informant" who might then introduce them to other people or regions in the setting (Mason, 2002).

Mason (2002) says that the researcher must ask himself/herself whether he/she have gained "acceptance" from all of those involved, and what exactly that acceptance might mean. She further explains that the answers to such questions will of course be tentative, since the researcher simply will not always-or ever-be in a position to know how others see him/her, but he/she should ensure that the researcher continue to analyze himself/herself, and interactions with others, so that he/she can make judgements about these issues. Relationships in research settings are likely to develop and change over time, in some cases becoming very close, and sometimes becoming difficult or fractured also researchers may develop friendships, or spend large amounts of time in the company of people they dislike, observing or participating in activities which they do not care for (Mason, 2002). The researcher has to live through and manage these relationships and situations in a process which is simultaneously personal, emotional, physical and intellectual (Mason, 2002).

\subsection{Data Gathering as an Ethnographer}

Since a basic idea on role of an ethnographer is now gathered, the data gathering process involved in ethnography is discussed below. Mason (2002: 87) says, "If you are intending to enter a setting or situation to carry out some form of observation, then you will need to prepare yourself not just for the process and technique of observance, but also for social interaction. You will be variously involved in observing, participating, interrogating, listening, communicating, as 
well as a range of other forms of being, doing and thinking. This set of activities, performed in a research setting, is often referred to as fieldwork. Doing fieldwork means observing all of the points ... about managing and orchestrating social interactions, albeit the nature of the interaction may be different".

Data sources are the places where data can be collected. It may an individual or it may be an event. According to Mason (2002), these are the possible data sources which can be seen in qualitative research; people (as individuals, groups or collectivities), organizations, institutions and entities, texts (published and unpublished sources including virtual ones), settings and environments (material, visual/sensory and virtual), objects, artefacts, media products (material, visual/sensory and virtual), events and happenings (material, visual/sensory and virtual).

Ethnographic researchers immerse themselves in the setting and collect data directly and systematically by participating, watching, and listening attentively (Kalou \& Sadler-Smith, 2015). Ethnographers are particularly focused on the need to collect data in such natural settings rather than conducting experiments in artificial environments that inevitably lack context of socially complex settings or surveying (by interview and questionnaire) research subjects away from the context/place of interest to the researcher (Sandiford, 2015).

According to Seneviratne (2010), the ethnographer has to engage with the question of how diverse and experimental material can become the kind of data which can be used to construct convincing and meaningful arguments. She further continues that such decisions should be based on grounded critical judgements of what each can offer in relation to the research question and their context. Even photographs can be useful to bring out what the ethnographic researcher intends to do. This is seconded by Emmison and Smith, "photographs may be helpful sometimes in recording the seen dimensions of social life. Usually they are not necessary" (Mason, 2002).

\subsection{Suggestion for the Analysis in an Ethnographic Research}

Ethnographers seek to gain an emic perspective, or the "native's point of view" of a specific culture (Eriksson \& Kovalainen, n.d.). This means that they try to look at the culture under study from the inside; through the meanings that the members of that culture live with (Eriksson \& Kovalainen, n.d.). In organizational ethnographic analysis presents the symbolic representations of actors' meanings - that is, the specific language, acts, and/or objects that carry and transmit human sensemaking as those actors create, experience, and attribute meaning to social realities (Ybema \& Kamsteeg, 2009).

Over the recent past, social scientists have increasingly focused on the usefulness of narratives for reporting and evaluating human experiences (Seneviratne, 2010). Accordingly, the power of narratives as a tool in analyzing ethnographic data is strongly recognized in the literature. Some researchers point out that the narrative mode is especially important to the character of ethnographic inquiry 
since it furnishes meaning and reason to reported events through contextual and processual representations (Seneviratne, 2010). In narrating events ethnographers can show how people act and react in particular social circumstances (Seneviratne, 2010). This approach allows ethnographers to "display the patterning of actions and interactions, its predictable routines and unpredictable ... crisis ... show the reader both the mundane and the exotic" (Seneviratne, 2010).

Finally, the overall significance of the ethnography can be conveyed through its narrative structure, "beyond the fragmentary narratives persons and circumstances are the meta-narratives that shape the ethnography overall" (Seneviratne, 2010). Ethnographers can carry out their task of transforming material from the field into the text by constructing narratives of everyday life. For this purpose, ethnographers need to critically develop the craft of storytelling (Seneviratne, 2010). By arming themselves with this powerful intellectual and aesthetic tool ethnographer can effectively engage with the task of storing other people's stories (Seneviratne, 2010). If we wish to understand the deepest and most universal of human experiences, if we wish our work to be faithful to the lived experiences of people ... or if we wish our privileges and skills to empower the people we study, then we should value the narrative (Seneviratne, 2010).

\section{Conclusion}

In this paper, I conferred an overview of how to incorporate one of the prominent methodologies in research accordingly. Basically, under the qualitative research approach, ethnography is the research method and the data gathering technique incorporated. Firstly, ethnography and organizational ethnography were defined and described as reviewed in other existing researches. Then, the role of an ethnographic researcher is discussed along with the ethnographic self of a researcher. Finally, the data gathering and analysis techniques that might be incorporated while using ethnography or organizational ethnography as suggestions are written. Reflexivity in a study means thinking critically about what the researcher is doing and why, confronting and often challenging his or her own assumptions, and recognizing the extent to which his or her thoughts, actions and decisions shape how he or she researches and what he or she sees (Mason, 2002). Thus, the writer invites the future interested candidates on the same topic to evaluate further on the same and provide more comprehensive papers.

\section{Conflicts of Interest}

The author declares no conflicts of interest regarding the publication of this paper.

\section{References}

Blomberg, J., Burrel, M., \& Guest, G. (2009). An Ethnographic Approach to Design. In Human-Computer Interaction: Development Process (pp. 71-94). Boca Raton, FL: CRC Press. https://doi.org/10.1201/9781420088892.ch5 
Bryman, A., \& Bell, E. (2007). Business Research Method.

Collins, P., \& Gallinat, A. (2010). The Ethnographic Self as Resource: An Introduction. In P. Collins, \& A. Gallinat (Eds.), The Ethnographic Self as Resource: Writing Memory and Experience into Ethnography (pp. 1-24). Oxford: Berghahn Books.

Cunliffe, A. L. (2010). Retelling Tales of the Field in Search of Organizational Ethnography 20 Years On. Organizational Research Methods, 13, 224-239. https://doi.org/10.1177/1094428109340041

Elizabeth, C.-B., Gaboury, I., Breton, M., \& Denis, J.-L. (2020). Organizational Ethnographic Case Studies: Toward a New Generative In-Depth Qualitative Methodology for Health Care Research? International Journal of Qualitative Methods, 8, 19-32.

Eriksson, \& Kovalainen (n.d.). Qualitative Methods in Business Research.

Huff, S., Rudman, D. L., Magalhães, L., Lawson, E., \& Kanyamala, M. (2020). Enacting a Critical Decolonizing Ethnographic Approach in Occupation-Based Research. Journal of Occupational Science. https://doi.org/10.1080/14427591.2020.1824803

Kalou, Z., \& Sadler-Smith, E. (2015). Using Ethnography of Communication in Organizational Research. Organizational Research Methods, 18, 629-655.

Linstead, S. A. (2017). Feeling the Reel of the Real: Framing the Play of Critically Affective Organizational Research between Art and the Everyday. Organization Studies, 39, 319-344. https://doi.org/10.1177/0170840617717552

Mason, J. (2002). Qualitative Research. London: SAGE Publications.

Sandiford, P. J. (2015). Participant Observation as Ethnography or Ethnography as Participant Observation in Organizational Research. In K. D. Strang (Ed.), The Palgrave Handbook of Research Design in Business and Management (pp. 411-446). London: Palgrave Macmillan. https://doi.org/10.1057/9781137484956_22

Seneviratne, S. J. (2010). Producing and (Re) Producing? An Ethnographic Narrative of Female Plantation and Apparel Workers of Sri Lanka.

Yanow, D. (2009). Organizational Ethnography and Methodological Angst: Myths and Challenges in the Field. Qualitative Research in Organizations and Management: An International Journal, 4, 186-199. https://doi.org/10.1108/17465640910978427

Yanow, D. (2012). Organizational Ethnography between Toolbox and World-Making. Journal of Organizational Ethnography, 1, 31-42. https://doi.org/10.1108/202466741211220633

Yanow, D., Ybema, S., \& Hulst, M. (2012). Practicing Organizational Ethnography. In The Practice of Qualitative Organizational Research: Core Methods and Current Challenges (pp. 331-350). London: SAGE.

Ybema, S., \& Kamsteeg, F. (2009). Making the Familiar Strange: A Case for Disengaged Organizational Ethnography. In S. B. Ybema, D. Yanow, H. Wels, \& F. H. Kamsteeg (Eds.), Organizational Ethnography: Studying the Complexities of Everyday Life (pp. 101-119). London: Sage. 